\title{
MODEL LAJU PERUBAHAN NILAI TUKAR RUPIAH (IDR) TERHADAP POUNDSTERLING (GBP) DENGAN METODE MARKOV SWITCHING AUTOREGRESSIVE $(M S A R)$
}

\author{
UQWATUL ALMA WIZSA, DODI DEVIANTO, MAIYASTRI \\ Program Studi Matematika, \\ Fakultas Matematika dan Ilmu Pengetahuan Alam, Universitas Andalas, \\ Kampus UNAND Limau Manis Padang, Indonesia, \\ email : uqwatulalma@gmail.com
}

\begin{abstract}
Abstrak. Perubahan struktur yang sering terjadi pada data deret waktu diduga dipengaruhi oleh suatu variabel acak tak teramati atau disebut dengan state. Perubahan struktur diidentifikasi dengan melihat pola nonlinier pada data yang biasanya berupa pelonjakan nilai yang sangat mencolok dan signifikan. Model Markov Switching Autoregressive (MSAR) oleh Hamilton merupakan suatu model yang dihasilkan dari penggabungan rantai Markov dan model klasik Autoregressive yang mampu menjelaskan perubahan struktur pada data deret waktu. Salah satu data yang sering mengalami perubahan struktur adalah data nilai tukar. Oleh karena itu, penelitian ini akan menentukan model terbaik bagi laju perubahan nilai tukar rupiah (IDR) terhadap poundsterling (GBP), menentukan besar peluang perpindahan dan bertahannya suatu state, serta besarnya dugaan durasi masing-masing state menggunakan metode Markov Switching Autoregressive (MSAR). Pada nilai tukar dimisalkan terdapat dua state apresiasi dan depresiasi. Diperoleh bahwa model terbaik yaitu MS(2)AR(1) dengan peluang transisi apresiasi ke apresiasi 0,979882, apresiasi ke depresiasi 0, 020118, depresiasi ke depresiasi 0,451971 , dan depresiasi ke apresiasi 0,548029. Sedangkan dugaan durasi pada apresiasi 49,7067 bulan dan durasi pada depresiasi 1,82462 bulan.
\end{abstract}

Kata Kunci: State, Rantai Markov, Stasioner, Parameter, Peluang Transisi

\section{Pendahuluan}

Data deret waktu seperti data-data di bidang ekonomi dan keuangan banyak ditemukan memiliki pola nonlinier dan mengalami perubahan struktur yang bisa disebabkan oleh krisis keuangan, perang, kebijakan pemerintah, bencana alam, dan lain sebagainya. Perubahan struktur dianggap dipengaruhi oleh suatu variabel acak tak teramati yang biasa disebut state.

Pemodelan deret waktu klasik yang umum digunakan seperti Autoregressive (AR), Moving Average (MA), Autoregressive Moving Average (ARMA), dan Autoregressive Integrated Moving Average (ARIMA) mengabaikan perubahan struktur yang terjadi pada data deret waktu. Hamilton (1989) mengenalkan model Markov Switching Autoregressive (MSAR) sebagai model deret waktu yang dapat menjelaskan perubahan struktur yang terjadi pada data. Model Markov Switching Autoregressive (MSAR) dapat menghitung besar peluang dan durasi untuk masing-masing state. 
Nilai tukar mata uang merupakan salah satu data yang sering ditemukan mengalami perubahan struktur. Dalam pemodelannya digunakan nilai laju perubahan nilai tukar dari hasil transformasi data nilai tukar yang sering dikenal sebagai nilai return. Peramalan terhadap laju perubahan nilai tukar dapat dimanfaatkan sebagai prediksi kondisi laju perubahan nilai tukar di masa yang akan datang untuk menghindari kerugian atau kesalahan pengambilan kebijakan dalam perekonomian.

Pemodelan laju perubahan nilai tukar rupiah (IDR) terhadap poundsterling (GBP) menggunakan model Markov Switching Autoregressive (MSAR) pada penelitian ini akan mencari model terbaik bagi data laju perubahan nilai tukar rupiah terhadap poundsterling, menentukan peluang transisi pada masing-masing state dan berpindah pada state lain, serta menentukan durasi laju perubahan nilai tukar bertahan untuk masing-masing state.

\section{Model Markov Switching Autoregressive (MSAR)}

Data nilai tukar termasuk sebagai data deret waktu. Data deret waktu merupakan rangkaian data yang berupa nilai pengamatan yang diukur selama kurun waktu tertentu, berdasarkan waktu dan interval yang sama. Data yang akan dianalisa dalam deret waktu haruslah bersifat stasioner. Stasioner berarti data tidak mengalami kenaikan atau penurunan pada periode waktu, data berfluktuasi di sekitar nilai tengah yang konstan sehingga tidak bergantung pada waktu, dan ragam dari fluktuasi yang terjadi pada data konstan setiap waktu. Kestasioneran diperlukan untuk memperkecil kekeliruan pada model. Untuk menguji suatu data stasioner atau tidak dilakukan dengan uji Augmented Dickey-Fuller. Hipotesis yang digunakan dalam uji ini yaitu

$$
\begin{aligned}
& H_{0}: \delta=0, \\
& H_{1}: \delta \neq 0 .
\end{aligned}
$$

Statistik uji Augmented Dickey-Fuller sebagai berikut

$$
A D F=\frac{\hat{\delta}}{S E(\hat{\delta})},
$$

dimana $S E(\hat{\delta})$ adalah standard error untuk $\hat{\delta}$. Kriteria pengambilan keputusannya yaitu jika $\mid$ statistik $-t A D F|>|$ statistik $-t$ kritis $(t-t a b e l) \mid$ maka tolak $H_{0}$ dengan kata lain data stasioner, dan sebaliknya [1].

Data yang tidak stasioner dapat diubah menjadi stasioner dengan melakukan differencing (pembedaan) dan transformasi Box-Cox. Pada data nilai tukar mata uang dapat digunakan transformasi dalam bentuk return atau nilai laju perubahan dengan formula sebagai berikut.

$$
R=\ln \left(\frac{z_{t}}{z_{t-1}}\right)
$$

Rantai Markov menjadi dasar dalam model Markov Switching Autoregressive (MSAR). Rantai Markov merupakan suatu teknik yang dapat digunakan untuk memperkirakan perubahan di waktu yang akan datang atas dasar perubahan dari 
masa lalu. Misalkan $s_{t}$ adalah state yaitu suatu variabel acak yang diasumsikan sebagai bilangan bulat $1,2, \cdots, N$. Anggap bahwa peluang dari suatu $s_{t}$ yang sama dengan suatu nilai tertentu $j$ hanya bergantung pada nilai sebelumnya $s_{t-1}$. Maka suatu rantai Markov didefinisikan sebagai [2]:

$$
P\left\{s_{t}=j \mid s_{t-1}=i, s_{t-2}=k, \cdots\right\}=P\left\{s_{t}=j \mid s_{t-1}=i\right\}=p_{i j},
$$

dimana $p_{i j}$ disebut peluang transisi yang memenuhi

$$
p_{i 1}+p_{i 2}+\cdots+p_{i N}=1 \text {. }
$$

Peluang transisi $p_{i j}$ menyatakan peluang dari state $j$ setelah kejadian state $i$.

Model Markov Switching Autoregressive (MSAR) mengontrol suatu perubahan struktur dengan suatu state yang tak teramati yang memenuhi orde pertama rantai Markov. Sifat Markov mengatur nilai peubah state bergantung pada nilai sebelumnya. Hamilton (1989) merumuskan bentuk umum model Markov Switcing Autoregressive sebagai berikut [4].

$$
\left(z_{t}-\mu_{s_{t}}\right)=\sum_{i=1}^{N} \phi_{i}\left(z_{t-1}-\mu_{s_{t-1}}\right)+\epsilon_{t},
$$

dimana $\left\{z_{t}\right\}$ adalah data pengamatan, $\phi$ adalah koefisien Autoregressive, $s_{t}$ adalah state pada waktu $t, \mu$ konstanta yang bergantung pada state $s_{t}$ dan $\epsilon_{t}$ residual pada waktu $t$.

Fungsi kepekatan peluang atau densitas dari $z_{t}$ mengikuti variabel acak $s_{t}$ dengan nilai $j$ adalah sebagai berikut,

$$
f\left(z_{t} \mid s_{t}=j ; \mu_{j}, \sigma_{j}{ }^{2}\right)=\frac{1}{\sqrt{2 \pi} \sigma_{j}} \exp \left(\frac{-\left(z_{t}-\mu_{j}\right)^{2}}{2 \sigma_{j}^{2}}\right),
$$

untuk setiap $j=1,2, \cdots, N[4]$.

State tak teramati $\left\{s_{t}\right\}$ diduga dihasilkan oleh beberapa distribusi peluang. Untuk peluang tak bersyarat $s_{t}$ yang bernilai $j$ dinotasikan dengan $\pi_{j}$ sebagai

$$
p\left(s_{t}=j ; \theta\right)=\pi_{j},
$$

untuk setiap $j=1,2, \cdots, N$. Peluang $\pi_{1}, \pi_{2}, \cdots, \pi_{N}$ termuat dalam $\theta$, dimana $\theta=$ $\left(\mu_{1}, \mu_{2}, \cdots, \mu_{N}, \sigma_{1}^{2}, \sigma_{2}^{2}, \cdots, \sigma_{N}^{2}, \pi_{1}, \pi_{2}, \cdots, \pi_{N}\right)$. Peluang dari kejadian bersama $s_{t}=j$ dan $z_{t}$ yang jatuh pada interval $[c, d]$ dapat dihitung dengan

$$
\begin{aligned}
p\left(z_{t}, s_{t}=j ; \theta\right) & =f\left(z_{t} \mid s_{t}=j ; \mu_{j}, \sigma_{j}{ }^{2}\right) P\left\{s_{t}=j ; \theta\right\} \\
& =\frac{\pi_{j}}{\sqrt{2 \pi} \sigma_{j}} \exp \left(\frac{-\left(z_{t}-\mu_{j}\right)^{2}}{2 \sigma_{j}^{2}}\right)
\end{aligned}
$$

Fungsi densitas tak bersyarat dari $z_{t}$ dapat diperoleh dengan menjumlahkan persamaan (2.9) untuk setiap kemungkinan nilai $j$

$$
f\left(z_{t} ; \theta\right)=\sum_{j=1}^{N} p\left(z_{t}, s_{t}=j ; \theta\right) .
$$


Pendugaan parameter model dapat dilakukan menggunakan metode Maksimum Likelihood Estimation (MLE). Langkah pertama yang harus dilakukan untuk melakukan estimasi parameter adalah menentukan fungsi densitas yang kemudian dibentuk menjadi fungsi log-likelihood. Berdasarkan model Markov Switching Autoregressive (MSAR) (2.5) dan persamaan (2.6) dengan menggunakan analisa sederhana yaitu menggunakan model markov switching dengan dua-state dan model autoregressive dengan orde satu, diperoleh fungsi densitasnya [2].

$$
f\left(z_{t} \mid s_{t}, s_{t-1}, \Omega_{t-1} ; \theta\right)=\frac{1}{\sigma \sqrt{2 \pi}} \exp \left(-\frac{\left(\left(z_{t}-\mu_{s_{t}}\right)-\phi_{1}\left(z_{t-1}-\mu_{s_{t}}\right)\right)^{2}}{2 \sigma^{2}}\right)
$$

dimana

$$
\begin{aligned}
\Omega_{t-1}=\left(z_{t-1}, z_{t-2}, \cdots\right) & \text { populasi data pengamatan, } \\
\theta=\left(\mu_{1}, \mu_{2}, \sigma^{2}, \phi_{1}\right): & \text { populasi parameter model } \operatorname{MS}(2) \operatorname{AR}(1) .
\end{aligned}
$$

Fungsi densitas $z_{t}$ diperoleh dengan menghitung kemudian menjumlahkan fungsi densitas bersama untuk setiap kemungkinan nilai $s_{t}$ dan $s_{t-1}$ sebagai berikut

$$
\begin{aligned}
f\left(z_{t} \mid s_{t}, s_{t-1}, \Omega_{t-1} ; \theta\right) & =\sum_{j=1}^{N} \sum_{i=1}^{N} f\left(z_{t}, s_{t}=j, s_{t-1}=i \mid \Omega_{t-1} ; \theta\right) \\
& =\sum_{j=1}^{N} \sum_{i=1}^{N} f\left(z_{t} \mid s_{t}, s_{t-1}, \Omega_{t-1} ; \theta\right) P\left(s_{t}=j, s_{t-1}=i \mid \Omega_{t-1} ; \theta\right)
\end{aligned}
$$

Untuk menentukan peluang state saat $t$ dari pengamatan sebelumnya hingga pengamatan ke-t dilakukan proses filtering dan smoothing. Proses filtering dijalankan untuk mendapatkan peluang nilai suatu state pada saat $t$ berdasarkan data pengamatan hingga saat $t$. Persamaan yang dituliskan oleh Nelson untuk proses filtering [3] adalah sebagai berikut.

$P\left(s_{t}=j, s_{t-1}=i \mid \Omega_{t} ; \theta\right)=\frac{f\left(z_{t} \mid s_{t}=j, s_{t-1}=i, \Omega_{t-1} ; \theta\right) P\left(s_{t}=j, s_{t-1}=i \mid \Omega_{t-1} ; \theta\right)}{\sum_{j=1}^{N} \sum_{i=1}^{N} f\left(z_{t} \mid s_{t}, s_{t-1}, \Omega_{t-1} ; \theta\right) P\left(s_{t}=j, s_{t-1}=i \mid \Omega_{t-1} ; \theta\right)}$

Sehingga nilai filtered state probability untuk suatu state dapat dihitung dengan:

$$
P\left(s_{t}=j, s_{t-1}=i \mid \Omega_{t} ; \theta\right)=\sum_{i=1}^{N} P\left(s_{t}=j, s_{t-1}=i \mid z_{t}, \Omega_{t-1} ; \theta\right) .
$$

Untuk mendapatkan nilai estimasi yang lebih baik, dilakukan proses smoothing dimana peluang nilai state dihitung berdasarkan informasi dari seluruh data pengamatan. Berikut adalah persamaan untuk proses smoothing [3].

$P\left(s_{t}=j, s_{t+1}=k \mid \Omega_{T} ; \theta\right)=\frac{P\left(s_{t+1}=k \mid \Omega_{T} ; \theta\right) P\left(s_{t}=j \mid \Omega_{t} ; \theta\right) P\left(s_{t+1}=k \mid s_{t}=j, \Omega_{t} ; \theta\right)}{P\left(s_{t+1}=k \mid \Omega_{t} ; \theta\right)}$. 
Persamaan di atas dihitung untuk setiap kemungkinan nilai $k$, kemudian diperoleh besarnya peluang $s_{t}$ bernilai $j$ berdasarkan pengamatan hingga $t=T$, sebagai berikut.

$$
P\left(s_{t}=j \mid \Omega_{T} ; \theta\right)=\sum_{k=1}^{N} P\left(s_{t}=j, s_{t+1}=k \mid \Omega_{T} ; \theta\right) .
$$

Setelah mendapatkan nilai peluang $s_{t}$ melalui proses filtering dan smoothing maka dapat diperoleh fungsi densitas dari $z_{t}$ sebagai berikut

$$
f\left(z_{t} \mid s_{t}, s_{t-1}, \Omega_{T} ; \theta\right)=\sum_{j=1}^{N} \sum_{i=1}^{N} f\left(z_{t} \mid s_{t}, s_{t-1}, \Omega_{T} ; \theta\right) P\left(s_{t}=j, s_{t-1}=i \mid \Omega_{T} ; \theta\right)(2
$$

Dengan demikian, fungsi likelihood dan log-likelihood dapat ditulis menjadi

$$
\begin{aligned}
L(\theta) & =\prod_{t=1}^{T} f\left(z_{t} \mid s_{t}, s_{t-1}, \Omega_{T} ; \theta\right), \\
\ln L(\theta) & =\sum_{t=1}^{T} f\left(z_{t} \mid s_{t}, s_{t-1}, \Omega_{T} ; \theta\right) .
\end{aligned}
$$

Untuk dua-state model MSAR terdapat dua fungsi pembatas $\pi_{1}$ dan $\pi_{2}$, sehingga pendugaan maksimum likelihood ditentukan dalam fungsi Lagrange dari log-likelihood menjadi [2]:

$$
J(\theta)=\ln L(\theta)+\lambda\left(1-\pi_{1}-\pi_{2}\right) .
$$

Untuk memaksimumkan nilainya, fungsi tersebut didiferensialkan terhadap masingmasing parameter dalam $\theta=\left(\mu_{j}, \sigma_{j}^{2}, \pi_{j}, \phi_{j}\right)$ dan menyamakannya dengan nol. Diperoleh

$$
\begin{aligned}
\hat{\mu}_{j} & =\frac{\sum_{t=1}^{T} z_{t} P\left(s_{t}=j \mid z_{t} ; \hat{\theta}\right)}{\sum_{t=1}^{T} P\left(s_{t}=j \mid z_{t} ; \hat{\theta}\right)}, \\
\hat{\sigma}_{j}^{2} & =\frac{\sum_{t=1}^{T}\left(z_{t}-\hat{\mu}_{j}\right)^{2} P\left(s_{t}=j \mid z_{t} ; \hat{\theta}\right)}{\sum_{t=1}^{T} P\left(s_{t}=j \mid z_{t} ; \hat{\theta}\right)}, \\
\pi_{j} & =\frac{1}{T} \sum_{t=1}^{T} P\left(s_{t}=j \mid z_{t} ; \theta\right), \\
\hat{\phi}_{p} & =\frac{\sum_{t=1}^{T}\left(\sum_{j=1}^{N=1}\left(z_{t}-\hat{\mu}_{j}\right) P\left(s_{t}=j \mid \Omega_{T} ; \theta\right)\right)}{\sum_{t=1}^{T}\left(\sum_{j=1}^{N=2} P\left(s_{t}=j \mid \Omega_{T} ; \theta\right)\right)} .
\end{aligned}
$$

Selanjutnya durasi dari masing-masing state dapat diduga berdasarkan perolehan peluang masing-masing state yang didapat dari model dengan menggunakan formula

$$
E(D)=\frac{1}{1-p_{j j}}
$$

Model terbaik diperoleh dengan membandingkan nilai Akaike's Information Criterion (AIC), Bayesian Information Criterion (BIC), dan Hannan and Quinn Criterion $(H Q C)$. Model terbaik adalah model dengan nilai AIC, BIC, dan HQC terkecil. 


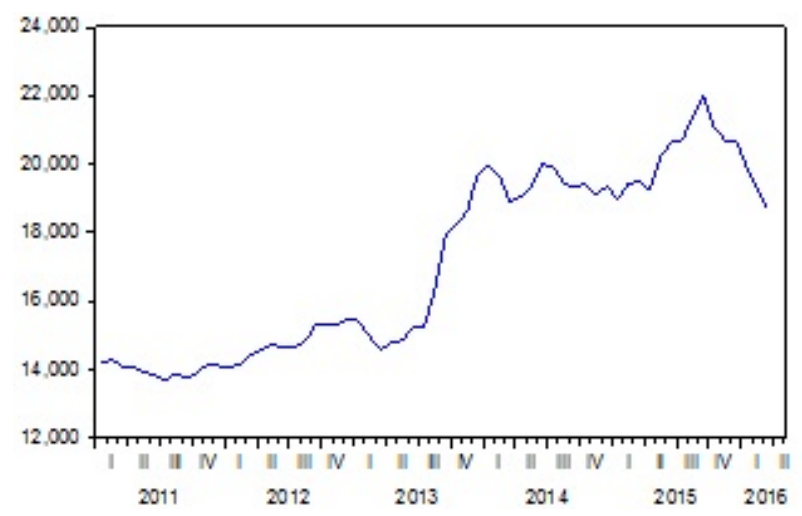

Gambar 1. Plot Data Nilai Tukar Rupiah Terhadap Poundsterling

Persamaan AIC, BIC, dan HQC dalam pemilihan model adalah

$$
\begin{aligned}
A I C & =-2 \log \hat{\sigma}^{2}+2 k, \\
B I C & =\log \hat{\sigma}^{2}+\frac{k \log n}{n}, \\
H Q C & =-2 \log \hat{\sigma}^{2}+2 k \log (\log n),
\end{aligned}
$$

dimana $\log \hat{\sigma}^{2}$ adalah ukuran likelihood, $k$ adalah banyak parameter, dan $n$ adalah banyak pengamatan.

\section{Penerapan Model Markov Switching Autoregressive (MSAR) pada Nilai Tukar Rupiah Terhadap Poundsterling}

Penelitian ini menggunakan data bulanan nilai tukar rupiah (IDR) terhadap poundsterling (GBP) periode Januari 2011 hingga Maret 2016. Langkah pertama yang dilakukan dalam pemodelan ini adalah plot data, seperti terlihat dalam Gambar 1.

Dari Gambar 1 dapat dilihat bahwa nilai tukar mata uang rupiah terhadap poundsterling pada sampel ini mengalami perubahan kondisi antara sebelum dan setelah bulan ketujuh di tahun 2013. Perubahan kondisi ini menunjukkan sifat yang tidak linier dalam data. Sebelum bulan ketujuh tahun 2013 data dikatakan mengalami apresiasi, sedangkan pasca bulan ketujuh tahun 2013 data mengalami depresiasi.

Selanjutnya dilakukan transformasi data ke dalam nilai laju perubahan. Plot laju perubahan nilai tukar rupiah terhadap poundsterling diberikan dalam Gambar 2 .

Kondisi yang sama dengan plot nilai tukar rupiah terhadap poundsterling nampak dari sebaran plot data laju perubahan nilai tukar rupiah terhadap poundsterling. Hal ini menunjukkan bahwa pada laju perubahan nilai tukar mata uang rupiah terhadap poundsterling terdapat suatu perubahan atau pergantian struktur. Terjadinya perubahan struktur dari satu kondisi ke kondisi lain pada data ini mengidentifikasikan terdapat dua state pada data. Hal ini memungkinkan data laju 


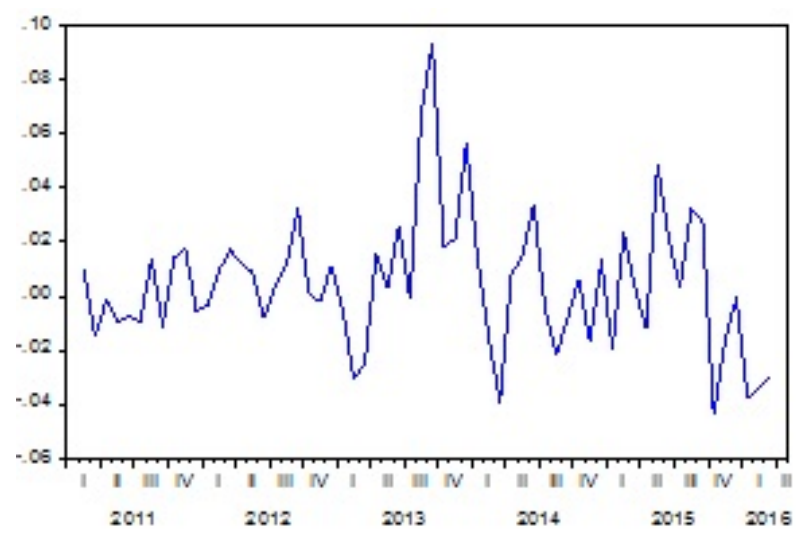

Gambar 2. Plot Data Laju Perubahan Nilai Tukar Mata Uang Rupiah Terhadap Poundsterling

\begin{tabular}{|c|c|c|c|}
\hline \multirow{2}{*}{\multicolumn{2}{|c|}{$\begin{array}{l}\text { Nilai statistik-t Augmented } \\
\text { Dickey-Fuller }\end{array}$}} & \multirow{2}{*}{$\begin{array}{c}\text { Nilai statistik-t } \\
-5,193046\end{array}$} & \multirow{2}{*}{$\frac{\text { Probabilitas }}{0,0001}$} \\
\hline & & & \\
\hline Nilai Kritis & $\begin{array}{c}1 \% \\
5 \% \\
10 \%\end{array}$ & $\begin{array}{l}-3,542097 \\
-2,910019 \\
-2,592645\end{array}$ & \\
\hline
\end{tabular}

Gambar 3. Hasil Uji Augmented Dickey-Fuller Data Laju Perubahan Nilai Tukar Mata Uang Rupiah Terhadap Poundsterling

perubahan pada nilai tukar ini dapat dimodelkan dengan metode Markov Switching Autoregressive (MSAR). Dalam kasus laju perubahan nilai tukar mata uang ini diasumsikan bahwa state pertama sebagai kondisi apresiasi dan state kedua yaitu depresiasi.

Selanjutnya data laju perubahan ini diuji kestasionerannya. Dengan menggunakan uji Augmented Dickey-Fuller diperoleh hasil pengujian pada Gambar 3.

Dari hasil pengujian pada Gambar 3, diperoleh bahwa nilai $t_{\text {stat }}$ sebesar $-5,193046$. Jika dibandingkan dengan nilai kritis pada taraf uji $10 \%$ senilai -2, 592645 didapatkan bahwa $\left|t_{\text {stat }}-A D F\right|$ jauh lebih besar dari |nilai kritis|. Ini berarti data laju perubahan nilai tukar mata uang rupiah terhadap poundsterling sudah stasioner.

Dengan identifikasi model Markov Switching Autoregressive (MSAR) menggunakan dua state dan orde Autoregressive satu sampai lima diperoleh Gambar 4.

Berdasarkan dugaan parameter pada masing-masing model pada Gambar 4, diperoleh bahwa model yang memiliki parameter yang signifikan hanya MS(2)AR(1). Pada kedua model tersebut peluang orde-1 pada MS(2)AR(1) bernilai 0,0617. Hal ini mengindikasikan bahwa dari kelima model hanya MS(2)AR(1) yang layak dijadikan sebagai kandidat model terbaik data sampel.

Model MS(2)AR(1) dinyatakan sebagai model terbaik, karena hanya satu model yang layak dijadikan kandidat model terbaik. Dari model MS(2)AR(1) diperoleh 


\begin{tabular}{|c|c|c|c|c|c|}
\hline & MS(2)AR(1) & MS(2)AR(2) & MS(2)AR(3) & MS(2)AR(4) & MS(2)AR(5) \\
\hline$\mu_{1}$ & $\begin{array}{c}0,001534 \\
(0,6762)\end{array}$ & $\begin{array}{c}0,004623 \\
(0,8473)\end{array}$ & $\begin{array}{c}0,001888 \\
(0,6340)\end{array}$ & $\begin{array}{c}-0,004925 \\
(0,6237)\end{array}$ & $\begin{array}{c}0,011040 \\
(0,0417)\end{array}$ \\
\hline$\mu_{2}$ & 0,074721 & 0,004623 & 0,073259 & 0,010330 & $-0,010576$ \\
& $(0,0001)$ & $(0,8488)$ & $(0,0025)$ & $(0,0907)$ & $(0,3478)$ \\
\hline$\phi_{1}$ & 0,253730 & 0,373780 & 0,287737 & 0,645349 & 0,616599 \\
& $(0,0617)$ & $(0,0064)$ & $(0,0473)$ & $(0,0022)$ & $(0,0115)$ \\
\hline$\phi_{2}$ & - & $-0,043874$ & $-0,098815$ & $-0,403802$ & $\begin{array}{c}-0,284398 \\
(0,3394)\end{array}$ \\
\hline$\phi_{3}$ & - & - & $0,088447)$ & 0,467306 & 0,317145 \\
& & & $(0,6196)$ & $(0,0166)$ & $(0,1905)$ \\
\hline$\phi_{4}$ & - & - & - & $-0,189424$ & 0,014455 \\
& & & & $(0,2623)$ & $(0,9437)$ \\
\hline$\phi_{5}$ & - & - & - & - & $-0,231972$ \\
& & & $0,2653)$ \\
\hline$\sigma$ & 0,019903 & 0,023385 & 0,019987 & 0,019531 & 0,018885 \\
& $(0,0000)$ & $(0,0000)$ & $(0,0000)$ & $(0,0000)$ & $(0,0000)$ \\
\hline$p_{11}$ & 0,979882 & 0,492601 & 0,979708 & $2,68 \mathrm{E}-10$ & 0,651753 \\
\hline$p_{22}$ & 0,451971 & 0,486445 & 0,462402 & 0,426175 & $1,30 \mathrm{E}-10$ \\
\hline
\end{tabular}

Gambar 4. Rangkuman Estimasi Parameter Masing-Masing Model

parameter $\mu_{1}=0,001534$ dan $\mu_{2}=0,074721$ menyatakan rata-rata state, $\sigma=0,019903$ menyatakan besar simpangan baku, diperoleh $\sigma^{2}=3,9612 \times 10^{-4}$ sebagai varian, dan parameter Autoregressive $\phi_{1}=0,253730$. Model ini dapat dituliskan secara lengkap dalam bentuk:

$$
\left(z_{t}-\mu_{s_{t}}\right)=0,253730\left(z_{t-1}-\mu_{s_{t-1}}\right)+\epsilon_{t} .
$$

Dari model di atas diperoleh peluang transisi state $p_{11}=0,979882, p_{12}=0,020118$, $p_{22}=0,451971$, dan $p_{21}=0,548029$. Selanjutnya dari peluang transisi dapat dicari durasi masing-masing state, durasi untuk apresiasi selama 49,7067 periode (bulan) sedangkan durasi depresiasi diperoleh sebesar 1,82462 periode (bulan).

\section{Kesimpulan}

Berdasarkan analisis yang telah dilakukan, dapat diperoleh kesimpulan sebagai berikut.

(1) Model terbaik yang diperoleh dari data laju perubahan nilai tukar rupiah terhadap poundsterling pada periode Januari 2011 sampai Maret 2016 adalah MS(2)AR(1) dengan bentuk model

$$
\left(z_{t}-\mu_{s_{t}}\right)=0,253730\left(z_{t-1}-\mu_{s_{t-1}}\right)+\epsilon_{t}
$$

dengan parameter $\mu_{1}=0,001534, \mu_{2}=0,074721, \sigma=0,019903$, dan $\phi_{1}=0,253730$. 
64 Uqwatul Alma Wizsa dkk.

(2) Jika diketahui saat $t-1$ laju perubahan nilai tukar mengalami apresiasi, maka peluangnya saat $t$ mengalami apresiasi adalah $p_{11}=0,979882$ dan peluangnya mengalami depresiasi sebesar $p_{12}=0,020118$. Jika diketahui saat $t-1$ laju perubahan nilai tukar mengalami depresiasi, maka peluangnya pada saat $t$ mengalami depresiasi adalah $p_{22}=0,451971$, dan peluangnya mengalami apresiasi adalah $p_{21}=0,548029$.

(3) Durasi laju perubahan nilai tukar rupiah mengalami apresiasi adalah 49, 7067 bulan dan durasi laju perubahan nilai tukar rupiah mengalami depresiasi adalah 1,82462 bulan.

\section{Daftar Pustaka}

[1] Gujarati, Damogar. 2004. Basic Econometrics. Fourth Edition. The McGrawHill Companies.

[2] Hamilton, J.D 1994. Time Series Analysis. New Jersey. Princeton Univercity Press.

[3] Kim C.J dan Nelson C.R 1999. State Space Models with Regime Switching, Classical and Gibs Sampling Approaches with Application. Cambridge, Ma. MIT Press.

[4] Xie, Yingfu, Jun Yu, dan Bo Ranneby. 2007. A General Autoregrressive Model with Markov Switching: Estimation and Consistency. Swedish University of Agricultural Science. Swedish 